\title{
Teaching Outside Specialization from the Perspective of Science Teachers
}

\author{
Annalene Grace E. Co1, Charmaine Ruth G. Abella1, Fhrizz S. De Jesus ${ }^{2}$ \\ ${ }^{1}$ Quirino State University, Maddela Campus, Maddela, Philippines \\ ${ }^{2}$ Nueva Ecija University of Science and Technology, Atate Campus, Palayan City, Philippines \\ Email: annalenegrace.co@qsu.edu.ph, charmaineruth.abella@qsu.edu.ph,fhrizzdejesus01@gmail.com
}

How to cite this paper: Co, A.G.E., Abella, C.R.G. and De Jesus, F.S. (2021) Teaching Outside Specialization from the Perspective of Science Teachers. Open Access Library Journal, 8: e7725.

https://doi.org/10.4236/oalib.1107725

Received: July 3, 2021

Accepted: July 30, 2021

Published: August 2, 2021

Copyright $\odot 2021$ by author(s) and Open Access Library Inc.

This work is licensed under the Creative Commons Attribution International License (CC BY 4.0).

http://creativecommons.org/licenses/by/4.0/

\begin{abstract}
This study aimed to describe and analyze the lived experiences of Senior High School Science teachers in the district of Nagtipunan teaching subjects outside their specialization. A qualitative research design using a hermeneutic phenomenological approach was employed in the conduct of this study. The study was participated in by six (6) Senior High School Science full-time teachers with three years employment in the school during the school year 2019-2020 who were selected purposively. Through an in-depth, face-to-face semi-structured interview, written essay, and focus group discussion, creative self-expressive storytelling activities were conducted with the participants. Through these activities, the essence and meaning of teaching subject outside specialization were further interpreted and elaborated in six (6) themes: (a) Teacher's Learning \& Challenging Experiences; (b) Factors of Teaching Subject Outside Specialization; (c) Challenges and Difficulties Faced by the Teachers; (d) Teaching Strategies \& Coping Mechanisms; (e) Teacher's Desirable attribute in Teaching Subject Outside Specialization; and, (f) Implications of Teaching Subject Outside Specialization. Answers to each theme category were examined and narrowed. Thereby arriving at one concept, the teaching and learning process in teaching out-of-field is at stake and detrimental to the education system. The experiences of teachers teaching outside specialization manifested difficulties, challenges, and negligence and became common practice. An issue on quality education has been taken for granted hence, to be remediated.
\end{abstract}

\section{Subject Areas}

Education, Social Science

\section{Keywords}

Lived Experiences, Conversation Partners, Specialized Teachers, Non-Specialized Teachers, Out-of-Field Teaching 


\section{Introduction}

Quality education is the heart for sustainable development and a powerful catalyst towards developing more just, humane and equitable societies [1]. Quality education has become critical in many countries that are expanding enrolments rapidly to achieve Education for All [2]. Recently, Education systems are under strain, but the assumption that there is a compromise between access and quality is flawed. In countries with constrained resources, the successful effort to increase access to primary education has often led to declining quality of education [3].

[4] Public school teachers play an important role in our society, especially for the students. Quality education requires quality teachers [5]. The quality of education directly related to the quality of instruction in the classrooms and the availability of competent teachers is vital in constructing the educational system [6]. The most significant factor in improving student achievement is employing qualified teachers in all schools [7]. Teachers should give the most appropriate tools, including content knowledge and skills and teaching methodology, to do their work professionally [8]. Teacher competency plays a tremendous role in student performance [9]. Moreover, effective teachers possess broad knowledge in the content areas that they teach and often have majored in those specialized areas [10].

However, teacher quality has a widely discussed issue in education [11]. One of the problems that caught attention is teaching outside their specialization, mismatched subject assignments in grade school, high school, and tertiary level [12]. The phenomenon of teaching subjects outside the discipline, where teachers have lack educational background or training, has been neglected [13]. It is a crucial issue because highly qualified teachers may, in actuality, become highly unqualified if they are assigned to teach subjects for which they have little training or education. Unqualified teachers may negatively impact student's achievement and be detrimental to the educational process [14] [15].

In the recent $\mathrm{K}$ to 12 Program, the implementation of Senior High School faced new challenges due to the shortage of teachers. Science specialized teachers have the predicament of teaching outside their field of specialization or expertise, basically, this is one of the reasons why this study was limited only to the science teachers. Senior High School Science teachers also face this apparent dilemma that beginner teachers in school lack qualified teachers.

This prompted the researchers to study the lived experiences of the Senior High School Science teachers who are teaching subjects outside their specialization. This study will explore the lived experiences, challenges they faced, and strategies they used in teaching subjects outside their field. This study contributes to the formulation of plans/policies needed for management, supervision, and instruction.

\subsection{Review of the Literature}

This study takes a bold and innovative stance drawn from Vygotsky's (1978) social constructivist theory and Gadamer's $(1975,1976)$ hermeneutic phenome- 
nological philosophy to develop a broader context from which an in-depth understanding of the "real-life" experiences of teaching subject outside specialization is analyzed. Gadamer's $(1975,1976)$ hermeneutic philosophy supports a deeper understanding of the complex lived experiences and the meaning of teaching subjects outside the discipline. Vygotsky's (1978) theories about the more knowledgeable other (MKO) and the zone of proximal development (ZPD) provided tools to encounter an in-depth understanding of the meaning and the essence of their experiences in teaching subjects outside specialization and the learning environment.

The complexity and taking-for-granted experiences of the Senior High School Science teachers teaching subjects outside specialization also draw concepts from the philosophical foundation of Constructivism, where its central idea states that "people construct their meaning of life-based on reality." Constructivists view reality as a socially constructed truth of life [16].

The essence and meaning of teaching subject outside specialization are further interpreted and elaborated in six themes: (a) Teacher's Learning and Challenging Experiences; (b) Factors of Teaching Subject Outside Specialization; (c) Challenges and Difficulties Faced by the Teachers; (d) Teaching Strategies and Coping Mechanisms; $€$ Teacher's Desirable Attribute in Teaching Subject Outside Specialization; and, (f) Implications of Teaching Subject Outside Specialization.

\subsubsection{Teacher's Learning and Challenging Experiences}

The person and the job are linked in Kolb's experiential learning theory. It implies a valuable understanding of job match or mismatch, as well as determining how distinct person-work interactions affect performance or pleasure. Underlying this Experiential Learning Theory (ELT) entails people change, adapt, and capable of learning different types of skills. Teachers' adaptability towards challenges and difficulties in teaching subjects outside specialization helps lessen the predicament [14]. Effectiveness in teaching is in a dynamic match between the teacher and the job. According to Hobbs [13], positive, negative, and challenging experiences in education outside the area of expertise are experienced by novice and veteran teachers. It has been overlooked, and least understood. It became a widespread and continuing practice, but those who experienced the difficulties suffer the consequences of being misaligned, lack of confidence, and guilt [17].

\subsubsection{Factors of Teaching Subject outside Specialization}

Several factors brought teachers to teach outside their expertise, such as shortage of teachers, subject misalignment, teacher attrition, hiring requirements, and staffing management. [17] The data emerging from research into teacher supply and demand demonstrate how poor attraction and retention of teachers. This increases teacher attrition to the extent of teaching outside specialization. Misalignment of the subject assignment is not merely due to teachers' lack of teachers but to how hiring, staffing, and planning were implemented in school [14]. 
Shortages of qualified teachers led to an increase in teachers' teaching outside their subject areas, undermining a common practice without appropriate response and mitigation [18].

\subsubsection{Challenges and Difficulties}

Teaching subject outside specialization has adverse effects on teachers themselves and their student's learning [19]. [20] Teachers expressed many challenges they experienced with an out-of-field assignment, including difficulties in dealing with student motivation and concerns over selecting appropriate instructional strategies, lack of background knowledge, and lack of support [11]. Teaching outside specialization, teachers felt inadequate and stressed while working with students.

Teaching outside areas of expertise brought complex challenges, and teachers express concern and apprehension when dealing with this situation. Teachers' lack of confidence when teaching topics outside their scope of knowledge is manifested in different ways, such as when preparing lesson plans, choosing or devising activities and analogies to aid students' questions, setting up laboratory experiments, choosing classroom activities, linking and applying various concepts and principles to everyday life situations, generating students' interest and passion for the subject [21].

\subsubsection{Teaching Strategies and Coping Mechanism}

Teaching strategies and coping mechanisms are anchored to Lee Shulman's Subject Matter Knowledge (SMK) and Pedagogical Content (PCK) associated with Technological Pedagogical Content Knowledge (TPACK) [22]. They are essential teaching methods and strategies to cope with the challenges and difficulties in teaching subjects outside specialization. The articulating link of these two components: Knowledge and Teaching, in understanding how a particular feature of subject matter is organized, adapted, and represented for instruction is referred to as Pedagogical Content Knowledge (PCK). The content knowledge that deals with the teaching process and strategies mean the teaching method or the amount and organization of knowledge per se in teachers' minds. On the other hand, pedagogical knowledge means the, how of teaching or the ability to teach, usually acquired through education coursework and personal experiences [16].

Moreover, TPACK describes the kinds of knowledge needed by a teacher for effective technology integration. The TPACK framework emphasizes how the connections among teachers' understanding of content, pedagogy, and technology interact with one another to produce effective teaching [22]. Strategies such as technology integration and hands-on exploration of ICT tools appeared more advantageous for fostering knowledge and technological pedagogical content knowledge [23].

\subsubsection{Teacher's Desirable Attributes}

Teacher's attitude towards teaching subjects outside specialization is crucial for 
effective teaching. Teachers' experience in the field develops various levels of expertise to acquire the art, science, and technique of teaching [5]. There is a positive relationship between teacher quality as "enthusiasm, creativity, flexibility and adaptability and school success of its students. The teacher who has the desire to share the love of the subject with the students can make the material being taught stimulating and enjoyable, improvise and adapt to new demands and new challenges, and learn and improve teaching methods [24].

\subsubsection{Implications of Teaching Subject outside Specialization}

The effect of out-of-field teaching adds complexity to the educational system that affects learners, colleagues, parents, governing bodies, and school management. It puts extra strain on school staffing management and jeopardizes teaching and quality learning [15]. It lowers the quality of instruction, affects student's achievements [19]. In addition, the teacher feels inadequacy and incompetence, lack of cognitive challenge, and difficulty bringing the subject alive for students due to limited knowledge [20].

Moreover, teaching outside the area of specialization may disrupt teacher's development and may lead them to exit the profession [13]. Teachers teaching outside their field, which they have not been prepared for, lack of training and support were neglected. Government, policymakers, and administrators are called attention to this matter to be enjoined to provide adequate support, training, and funds to prepare teachers to become equipped and practical [25]. Thus, the phenomenon of teaching outside specialization should be recognized to provide practical, competent teaching and quality education.

\section{Methodology}

\subsection{Research Design}

In the conduct of this study, a qualitative research design using a hermeneutic phenomenological approach was employed. Gadamer (1975) saw conversation and interaction in hermeneutics as an "art" and not a mechanical process, although used as tools to develop a fundamental understanding of the experience. Through language states, the consciousness of knowledge states, "it speaks of being and the world," giving meaning to the visible and invisible world and providing the researchers with an opportunity to also inquire about what is not said. The hermeneutic circle involves language and movement from self to experience and experience to self [26]. The hermeneutic phenomenology avoids the subject or object divide but rather underlines the inter-relationship between the experience and the person and sees language as the vehicle to carry participants' lived experiences. Gadamer's hermeneutic philosophy is an interpretive method that investigates the meaning of personal experiences about understanding human interpretations. At the same time, it attempts to "uncover and describe structures" towards a better understanding of lived experiences [27].

[28] The best criteria to determine hermeneutic phenomenology is when the 
research problem requires a profound understanding of the human experiences common to a group of people. This approach appears to be the most appropriate to describe the lived experiences of Senior High School Science teachers teaching subjects outside their specialization.

\subsection{Research Setting}

The study was conducted at all Public Schools offering Senior High schools in the District of Nagtipunan, Division of Quirino.

The study participants included six (6) Senior High School Science full-time teachers with three years of employment in the school during the school year 2019-2020. As stated in the introduction, science teachers were facing difficulties in teaching science subjects because of different backgrounds. Therefore, the scope of this study was only limited to the science teachers.

\subsection{Sampling}

Purposive sampling was used to identify the primary participants. They were selected based on judgment and the purpose of the research. Participants who have had experiences relating to the phenomenon were chosen.

\subsection{Data Collection}

This study used creative self-expressive storytelling activities through an in-depth, face-to-face semi-structured interview, written essay, and focus group discussion with participants.

An overarching question and some open-ended, probing interview questions were asked to encourage the conversation partners to describe their experiences. A self-made questionnaire was provided, and a written essay was queried from the conversation partners. The questionnaire was created using the data gathered and double-checked by the researchers' mentors. The instrument's dependability coefficient was evaluated and measured at.860, indicating that the instrument has acceptable internal consistency. The validity of the research instrument was established by submitting the constructed research instrument to specialists for feedback, who gave it a 4.24 weighted mean with a verbal interpretation of "very good." Following distribution, the completed questionnaires were collected and the data was tallied for analysis. During the interview, two audio recorders were used to record the conversation.

The first part involved questions about the demographic profile of the participants in terms of gender, civil status, highest educational attainment, the field of specialization a.) major and b.) minor, and subjects taught a.) specialized and b.) non-specialized. The second part pertained to the questions that revealed the participants' lived experiences in teaching subjects outside specialization. Six (6) questions were asked, which encompass six (6) different components: learning \& challenging experiences, factors of teaching outside discipline, challenges \& difficulties faced in education outside specialization, teaching strategies \& coping 
mechanisms, teacher's desirable attributes, and implications of teaching subject outside the domain.

During the interviews, FGDs were conducted. A focus group discussion (FGD) is a useful technique to bring people together who have comparable backgrounds or experiences to talk about a certain issue. It was used in finding depth meaning from the responses.

Before the actual conduct of the survey questionnaire, a pilot study involving a sample of 3 Senior High School teachers teaching subjects outside specialization in the Junior High School of Nagtipunan National High School was conducted to validate the content of the questionnaire in terms of relevance, accuracy, and wording. The results were analyzed using the guidelines for the analysis of interview data. The appropriate changes based on the lessons learned from the pilot testing and the suggested changes concerning the instrument were made to the final copy of the questionnaire.

\subsection{Data Analysis}

To facilitate an in-depth, objective description and analysis of the lived experiences of the Senior High School Science teachers teaching subjects outside specialization, this study was guided by the guidelines for the analysis of interviews. Using such guidelines that explain the procedures in analyzing the interview data concretely, the researchers went through the following rigorous steps in analyzing and synthesizing the transcripts:

1. Transcription process wherein the researchers have repeatedly listened to the audio recording of each interview to become familiar with the words of the interviewee/informant to develop/create a holistic sense, the "gestalt."

2. They were delineating units of general meaning. The researchers carefully determined whether the statements of the conversation partners answered and illuminated the research question. Words that appear to address the phenomenon were studied and noted as a unit of relevant meaning, while irrelevant statements were discarded. Other redundant teams were eliminated.

3. Clustering units of meaning to form themes that are significant topics or units of significance. After which, the researchers thoroughly examined the groups of units of relevant meaning to determine the central issue conveyed by the essence of the clusters.

4. Summarize each interview, validate and modify. A summary that incorporates all the themes elicited from the data gives a holistic context. Whatever the method used for phenomenological analysis, the investigator aims to reconstruct the inner world of experience of the subject. Each individual has his way of experiencing temporality, spatiality, materiality, but each of these coordinates must be understood about the others and the whole inner world.

5. General and unique themes for all the interviews and composite summary. As the process outlined in points 1 to 4 has been done for the interviews, articles common to most of the discussions and individual variations were identified. 
Care must be taken not to cluster common themes if significant differences exist. The researchers concluded the explication by writing a composite summary, reflecting the context or "horizon" from which the themes emerged. The researcher, at this point, transforms participants' everyday expressions into expressions appropriate to the scientific discourse supporting the research. Hence, good analysis is not generated by rigorous data alone but by going beyond the data to develop ideas.

\subsection{Ethical Considerations}

The interaction between researchers and participants can be ethically challenging for the former, as they are personally involved in different stages of the study [29]. To meet the ethical consideration of the study, the researchers complied with prevailing ethical and legal requirements related to the conduct of the study. This research implemented several vital phrases that protect the rights of the participants.

Voluntary participation. The participants were not coerced into participating in research. This is especially relevant where the researchers relied on captive audiences for the subjects.

Inform consent. Prospective research participants were fully informed about the procedures and risks involved in research and ask them to indicate their willingness to participate by signing the consent.

Risk of harm. Participants were not put into a situation where they were at risk of damage due to their participation. Liability can be defined as both physical and psychological. These are two standards that were applied to help protect the privacy of research participants.

Confidentiality. Participants were assured that identifying information would not be made available to anyone directly involved in the study. Coded names and password-protected audio recorders were used to ensure confidentiality.

Anonymity. The standard, which essentially means that the participant will remain anonymous throughout the study, was strictly adhered to.

\section{Results and Discussions}

After the thorough and rigorous data explication and analysis, the researchers examined the categories, themes, and findings from the product in the initial data and narrowed her research to one core concept. After cutting out redundancy, the researchers trimmed it down into six essential themes. The six themes were drawn out from the interview, essay, and focus group discussion conducted to each participant are: (a). Teacher's Learning and Challenging Experiences; (b) Factors of Teaching Subject Outside Specialization, (c) Challenges and Difficulties Faced by the Teachers; (d) Teaching Strategies and Coping Up Mechanisms; (e) Teacher's Desirable Attributes in Teaching Subject Outside Specialization; and, (f) Implications of Teaching Subject Outside Specialization.

THEME 1: LEARNING \& CHALLENGING EXPERIENCES 
Findings revealed that teachers teaching outside specialization had learning \& challenging experiences. They were impacted positively \& negatively. The respondents were challenged. A challenge is a formal invitation or a summons to action. The extent and complexity of challenges differ. According to the respondents, they take challenges positively because they want to be engaged and created an impact in the school.

The respondents were also stressed. A body's response to a challenge or demand is called stress. Stress can be beneficial in small doses, such as when it helps you avoid danger or make a deadline. The respondents admitted that they understood why they were anxious to educate outside of their area of expertise. They used these experiences to strengthen themselves and prepare for the future, as well.

Lastly, the respondents were pressured from the preparation to delivery of the lesson. Interview revealed that their experiences made them more challenging, versatile, patient, committed, creative, resourceful, and passionate. It was a win-win situation.

\section{THEME 2: FACTORS OF TEACHING OUTSIDE SPECIALIZATION}

Lack of specialized teachers is the primary reason why there is out-of-field teaching. This is due to the low number of enrollees in a school in which the school couldn't hire many teachers to teach the different subjects. This is because there is a student-teacher ratio being followed. There was an average of 1:40 ratio, 1 Teacher for every 40 students. In the Senior High School curriculum, subjects every semester change, equally distributed to the available teachers.

THEME 3: CHALLENGES AND DIFFICULTIES FACED BY THE TEACHERS

Teachers teaching outside their specialization face crucial issues and challenges. These challenges are mainly due to limited subject matter knowledge (SMK) and influenced the teacher's pedagogical content knowledge (PCK), which is crucial in the preparation and actual teaching. They couldn't generate new activities, less creative, less confident, and followed the traditional method. Teachers need to spend a lot of time and effort studying the subject's content and plan carefully on the activities suitable for the student's abilities to ensure learning.

THEME 4: TEACHING STRATEGIES AND COPING UP MECHANISMS

Out-of-field teachers are employing various teaching strategies and coping up mechanisms. Based on the results, teachers often used active \& participative approaches like reporting, group activity, role-playing, and board works. To supplement the mastery of students' subject matter, videos from YouTube were downloaded and played in class. Guide questions were posted before the video presentation, and discussion or sharing is done after. Technological integration and hands-on exploration of ICT tools appeared to be more advantageous in teaching subjects outside specialization.

THEME 5: TEACHER'S DESIRABLE ATTRIBUTES IN TEACHING 


\section{SUBJECT OUTSIDE SPECIALIZATION}

Commitment and passion are the names of the game. The teachers' commitment encompasses their willingness to accept and embrace the challenge of teaching subjects outside specialization. This made them wholeheartedly took the subject loads and taught as if it were their major. They saw the challenge as an avenue for them to learn new things. Their passion led them to become more resourceful, creative, versatile, flexible, adaptable \& multi-faceted.

THEME 6: IMPLICATIONS OF TEACHING SUBJECT OUTSIDE SPECIALIZATION

Teaching subject outside specialization is probably unavoidable and prevalent to all issues, especially to schools categorized as small or medium. Teachers teaching subjects outside discipline are hoping that teaching out-of-field subjects would be temporary. Supposedly, expert teachers should handle Senior High School students because they have a high level of intelligence and can sense if they don't know what they are teaching. This leaves teachers feeling exposed. Despite the situation, teachers teaching subjects outside specialization remain positive towards it. They just ask for some support and action regarding the issue.

\section{Conclusions and Recommendations}

In general, the participants of this study described and expressed their experiences in teaching subjects outside specialization. They were able to identify essential factors that resulted in them teaching outside their area of specialization, such as shortage of qualified teachers, the issue under load, subjects misalignment, and staffing management. They face and embrace challenges encountered in teaching less familiar subjects in Senior High School like lack of learning references, lack of training and support, lack of planning and preparation of lessons. Participants in this study developed various teaching techniques and strategies specifically in Subject Matter Knowledge (SMK), Pedagogical Content Knowledge (PCK), and Technological Pedagogical Content Knowledge (TPACK) to cope with the challenges and difficulties. This research conveyed that the teacher's attributes also influenced teaching performance and capability in teaching out-of-field, personal, professional, and interpersonal characteristics.

Furthermore, teachers' lived experiences outside their specialization expounded and expressed the meaning of the essence of this study. Their experiences manifested difficulties, challenges and negligence and became common practice. An issue on quality education has been taken for granted hence, to be remediated. Participants' views, opinions, hopes, and desires were also solicited to discuss its implications. The teaching and learning process in teaching out-of-field is at stake and detrimental to the education system. When teachers are misaligned, it is suggested that they should be put into proper assignments, preferably to their unique, specialized subjects, and will be provided support. 
Workshops and training must be provided to develop their competence and to reduce the potential negative impact on teachers and learners. And soon, this issue will be given focus and be remediated.

Additional research in these areas would provide supplemental data to support teachers' lived experiences teaching outside specialization.

\section{Conflicts of Interests}

The authors declare no conflicts of interest.

\section{References}

[1] Department of Education (Philippines) (2016) Academic Track. http:/www.deped.gov.ph/k-to-12/about/k-to-12-basic-education-curriculum/acade mic-track/

[2] UNESCO (United Nations Educational, Scientific and Cultural Organization) (2017) Education for All 2015 National Review: Bangkok, 2017. United Nations Educational, Scientific and Cultural Organization (UNESCO), Paris.

[3] UNICEF (United Nations Children's Fund) (2016) Defining Quality in Education. Working Paper Series, United Nations Children's Fund (UNICEF), New York.

[4] De Jesus, F.S. and De Jesus, M.B. (2021) Spending Habits of Public School Teachers in Palayan City. Open Access Library Journal, 8, Article No. e6332. https://doi.org/10.4236/oalib.1106332

[5] Darling-Hammond, L. (1999) Teacher Quality and Student Achievement. A Review of State Policy Evidence. Education Policy Analysis Archives, 8, 1-44.

[6] Adeyemi, K.J. (2016) Effect of Teachers' Academic Qualification on Students' Performance at the Secondary Level. Academia.

[7] Adu, E.I. and Abe, T.O. (2013) Influence of Qualification On Development and Assessment of Computer Programmed Instructional Package on Energy Concept in Upper Basic Technology in Ekiti State. ARPN Journal of Science and Technology, 3, 611-618.

[8] Kumar, I.A. and Parveen, S. (2015) Teacher Education in the Age of Globalization. Research Journal of Educational Sciences, 1, 8-12.

[9] Carlson, J., Newsome, J.G., Gardner, A. and Taylor, J.A. (2016) A Framework for Developing Pedagogical Content Knowledge: The Role of Transformative Professional Development and Educative Curriculum Materials. Presented at the European Science Education Research Association Conference, September 2016, 1-37.

[10] Villaverde, N. (2017) Impact of Collaborative Specialization on 5th Grade Student Achievement in a Title I School. Harvard University Press, Cambridge.

[11] Caylao, F. (2015) My Thoughts of Out-of-Field Teaching. https://federationpress.com.au/product/encouraging-ethics-and-challenging-corrup tion/

[12] Weldon, P.R. (2016) Out-of-Field Teaching in Australian Secondary Schools. Australian Council for Educational Research, Victoria.

[13] Hobbs, L. (2012) Teaching "Out-of-Field" as a Boundary-Crossing Event: Factors Shaping Teacher Identity. International Journal of Science and Mathematics Education, 11, 271-297. https://doi.org/10.1007/s10763-012-9333-4

[14] Ingersoll, R., Merrill, L. and May, H. (2015) What Are the Effects of Teacher Educa- 
tion and Preparation on Beginning Teacher Attrition? Research Report No. \#RR-82, Consortium for Policy Research in Education, University of Pennsylvania, Philadelphia.

[15] Zhou, Y. (2013) The Relationship between School Organizational Characteristics and Reliance on Out-of-Field Teachers in Mathematics and Science: Cross-National Evidence from TALIS 2018. Asia-Pacific Education Researcher, 23, 483-497.

https://doi.org/10.1007/s40299-013-0123-8

[16] Kleickmann, T., Richter, D., Kunter, M., Elsner, J., Besser, M., Krauss, S. and Baumert, J (2012) Teachers' Content Knowledge and Pedagogical Content Knowledge: The Role of Structural Differences in Teacher Education. Journal of Teacher Education, 64, 90-106. https://doi.org/10.1177\%2F0022487112460398

[17] Du Plessis, A., Caroll, A. and Gilles, R. (2013) Understanding the Lived Experiences of Novice Out-of-Field Teachers about School Leadership Practices. Asia-Pacific Journal of Teacher Education, 43, 4-21. https://doi.org/10.1080/1359866X.2014.937393

[18] Kim, E.G. (2011) Out-of-Field Secondary School Teachers in Korea: Their Realities and Implications. KEDI Journal of Educational Policy, 8, 29-48.

[19] Childs, A. and McNicholl, J. (2007) Investigating the Relationship between Subject Content Knowledge and Pedagogical Practice through the Analysis of Classroom Discourse. International Journal of Science Education, 29, 1629-1653. https://doi.org/10.1080/09500690601180817

[20] Childs, A. and McNicholl, J. (2007) Science Teachers Teaching Outside of Subject Specialism: Challenges, Strategies Adopted and Implications for Initial Teacher Education. Teacher Development, 11, 1-20. https://doi.org/10.1080/13664530701194538

[21] Mizzi, D. (2013) The Challenges Faced By Science Teachers When Teaching outside Their Specific Science Specialism. Acta Didactica Naocensia, 6, 44-46.

[22] Koehler, M.J., Mishra, P., Kereluik, K., Shin, T.S. and Graham, C.R. (2014) The Technological Pedagogical Content Knowledge Framework. In: Spector, M., Merrill, M.D., Elen, J. and Bishop, M.J., Eds., Handbook of Research on Educational Communications and Technology, 4th Edition, Springer-Verlag, New York, 101-111.

[23] Koh, J.H.L. and Divaharan, S. (2013) Towards a TPACK-Fostering ICT Instructional Process for Teachers: Lessons from the Implementation of Interactive Whiteboard Instruction. Australasian Journal of Educational Technology, 29, 233-247.

[24] Panisoara, I.O., Duta, N., Panisoara, G. and Tomoaica, E. (2014) Teacher Profile in Romania: Defining Features and Priorities of the Training Programs in Teaching Career. Procedia-Social and Behavioral Sciences, 140, 396-400. https://doi.org/10.1016/j.sbspro.2014.04.441

[25] Nixon, R.S., Luft, J.A. and Ross, R.J. (2017) Prevalence and Predictors of Out-of-Field Teaching in the First Five Years. Journal of Research in Science Teaching, 54, 1197-1218. https://doi.org/10.1002/tea.21402

[26] St. Pierre, E.A. and Jackson, A.Y. (2014) Qualitative Data Analysis after Coding. Qualitative Inquiry, 20, 715-719. https://doi.org/10.1177\%2F1077800414532435

[27] Bitsch, V. (2005) Qualitative Research: A Grounded Theory Example and Evaluation Criteria. Journal of Agribusiness, 23, 75-91.

[28] Giorgi, A. (2014) An Affirmation of the Phenomenological Psychological Descriptive Method: A Response to Rennie (2012). Psychological Methods, 19, 542-551. 
[29] Sanjari, M., Bahramnezhad, F., Fomani, F.K., Shoghi, M. and Cheraghi, M.A. (2014) Ethical Challenges of Researchers in Qualitative Studies: The Necessity to Develop a Specific Guideline. Journal of Medical Ethics and History of Medicine, 7, Article No. 14. 